\title{
Performance of Three Level H-Bridge Inverter in Grid Connected Solar PV for Multifunctional Operations using Different Control Techniques
}

\author{
Darshni M. Shukla, Naimish Zaveri
}

\begin{abstract}
This paper presents multifunctional operation capability of three level cascade $H$ bridge inverter for grid connected solar $p v$ application. The solar panel and inverter are modelled for unbalance and nonlinear loads with three control techniques (pq,dq,cpt) and its performance is simulated in the MATLAB environment using SIMULINK and Sim Power System (SPS) toolboxes. The performance of inverter is evaluated for harmonics elimination, power factor correction apart from active and reactive power support to grid and nonlinear load .Performance of three level $\mathrm{H}$ bridge inverter is evaluated for both $P V$ mode and STATCOM mode using three control techniques for distribution grid.
\end{abstract}

Keywords: Active power filters, Cascaded H-bridge inverters, Compensation strategies, Conservative power theory, space vector modulation.

\section{INTRODUCTION}

In the last few decades, solar energy has been one of the most active research areas among renewable-energy sources. Photovoltaic systems connected to the electrical power grid are gaining more and more popularity as demand for energy is increasing worldwide. Multilevel inverters have been attracting more and more attention in the past few years as power converters in high voltage and high power grid connected applications due to their improved voltage qualities over the conventional two-level inverters. These MLIs with appropriate control improves the performance of the grid connected energy sources, even at lower switching frequencies with lesser filter components [1] [2]. The conventional grid connected inverters employ two stages of power converters for photovoltaic applications. The first stage is a dc/dc boost converter which is connected to the PV panel and tries to extract the maximum power from PV panels. The next stage is a voltage source converter which tries to transfer the electric power into the grid at unity power factor.

Revised Manuscript Received on February 28, 2020.

* Correspondence Author

Darshni M. Shukla*, Assistant Professor, Department of Electrical Engineering, Government Engineering College, Surat, India. E-mail: darshnishukla@yahoo.com

Naimish Zaveri, Professor, Department of Electrical Engineering, CK Pithawala College of Engineering \&Technology, College Surat, India.

(C) The Authors. Published by Blue Eyes Intelligence Engineering and Sciences Publication (BEIESP). This is an open access article under the CC-BY-NC-ND license http://creativecommons.org/licenses/by-nc-nd/4.0/

This kind of PV inverter, however, will lead to higher losses and complexity compared to single stage inverters due to insertion of dc/dc converters thus single stage transformer less topologies are becoming more popular due to compact size and higher efficiency. Smart inverters can perform multiple functions involving both reactive and real power control in addition to their main task of converting DC power to AC power.

These functions include voltage regulation, power factor control, active power controls, fault ride through, and frequency control, etc. Many research is going on to eliminate the usage of other reactive power compensation schemes by exploring multifunctional capability of inverter. The smart control of inverter is basically the ability to supply real power to local load up to the rated capacity of inverter and provide voltage support at the point of common coupling (PCC). Grid interconnection standards are also is being revised to facilitate the adoption of smart inverter functions [7].Among the various topologies, of MLIs the cascaded H-bridge (CHB) inverter is especially interesting for photovoltaic (PV) applications as it needs the minimum number of components for synthesizing the same number of voltage levels. It also provides several distinct DC links which allow the independent control of PV arrays [4] [5] [6].

The power conditioning stage interfacing the PV modules to the grid has attracted the attention of researchers. Several power conditioning methods and control strategies have been introducing for harmonics, reactive and unbalanced current compensation [11] [12].Active and reactive power control of three level inverter is proposed in [14] while active filtering capability of three level cascade $\mathrm{H}$ bridge inverter for various control is explore in [15].Most of the paper found in literature explore one or two functionality along with active power integration to grid. Multiple functionality of smart inverter proposed by various researcher is combined in this work.

The lineament of this paper is comparative analysis of the three most popular grid control techniques proposed in the literature to control three phase three level $\mathrm{H}$ - bridge inverter based photovoltaic plant. To explore its multifunctional capability the Maximum power point (MPP) control without DC/DC converter is also incorporated and develop a smart control for three level three phase voltage source inverter (VSI) which enables a Photovoltaic Power plant (PV) to operate as active filter, reactive power compensation, power factor correction and STATCOM in addition to operating as a source of renewable power generation. 


\section{Performance of Three Level H-Bridge Inverter in Grid Connected Solar PV for Multifunctional Operations using Different Control Techniques}

Different control methods are applied for power conditioning and hysteresis PWM is used for switching of the inverter and the performance of inverter will be analyzed and evaluated. The rest of the paper is organized under the following headings.

Section II begins with small description of system configuration with CHBMLI topology, followed by a detail description of all three control scheme for generation of required compensation currents in section III. Section IV presents the result of applying the different control strategies to a unique simulation platform designed in the Matlab-Simulink frame. Besides, this section presents different graphs and data tables to compare those results. Finally, in Section VI conclusion is presented.

\section{SYSTEM DESCRIPTION}

In this paper operation of three-phase, three-level cascade $\mathrm{H}$ bridge inverter for the grid-connected PV system with multiple functionality is explored. Conventional diagram of the proposed system is shown in figure 1. Three control technique PQ, DQ, CPT has been used for PV system active power injection as well as harmonics free current injection the grid. Hysteresis PWM technique has been used for switching of the inverter.

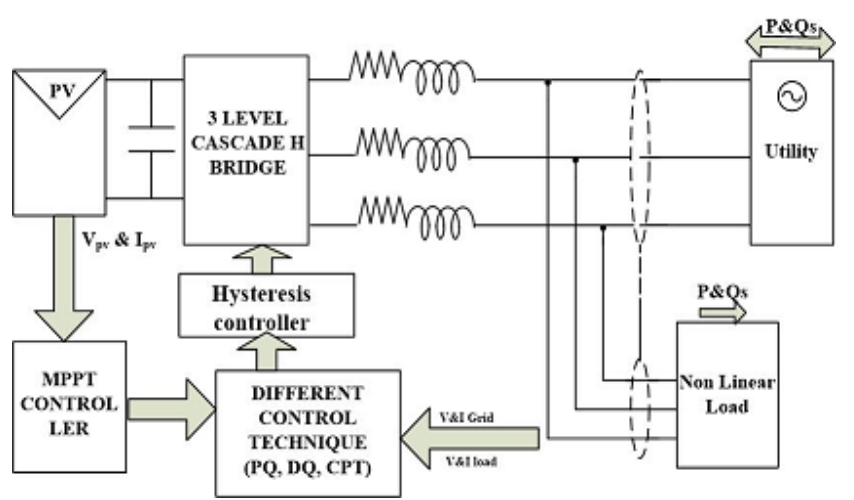

Fig.1 Block diagram of the proposed system

Incremental (In\&Co) conductance method is used for MPPT. Matlab Simulink based modelling has been done for evaluation of various control technique A relative study is carried out about its performance in the compensation by means of total harmonic distortion (THD) value measured in the source currents after compensation. Three phase thyristor bridge rectifier is chosen as a non-linear load with RL, RC and two single-phase bridge in two arms in output (unbalance as well as nonlinear).Model is simulated for both equal and unequal irradiance values.

\section{CONTROL STRATEGIES/ METHODS}

An overview of PQ, CPT and DQ control is presented in this section. Publication [10],[11][12], [13], is referred for reference current generation.

\subsection{Instantaneous power theory}

The instantaneous power theory block diagram of which is shown in fig.2, proposed by Akagi is also known a PQ theory. This theory is based on the Clarke transformation of voltages and currents from abc to $\alpha \beta 0$ orthogonal coordinates.
Applying the Clarkes transformation, the phase voltages in the $\alpha \beta 0$ coordinates have the form

$$
\left|\begin{array}{c}
\mathrm{v}_{0} \\
\mathrm{v}_{\alpha} \\
\mathrm{v}_{\beta}
\end{array}\right|=\sqrt{\frac{2}{3}}\left[\begin{array}{ccc}
\frac{1}{\sqrt{2}} & \frac{1}{\sqrt{2}} & \frac{1}{\sqrt{2}} \\
1 & \frac{1}{2} & -\frac{1}{2} \\
0 & \frac{\sqrt{3}}{2} & -\frac{\sqrt{3}}{2}
\end{array}\right] \quad\left[\begin{array}{c}
\mathrm{v}_{\mathrm{a}} \\
\mathrm{v}_{\mathrm{b}} \\
\mathrm{v}_{\mathrm{c}}
\end{array}\right]
$$

Likewise, the instantaneous currents can be transformed to $\alpha \beta 0$ coordinates. Three instantaneous powers: the zero sequence power (p_0) and real power (p), and the imaginary power (q) are determined from the instantaneous phase voltages and line currents in $\alpha \beta 0$ coordinates as

$$
\left[\begin{array}{c}
\mathrm{p}_{0} \\
\mathrm{p} \\
\mathrm{q}
\end{array}\right]=\left[\begin{array}{ccc}
\mathrm{v}_{0} & 0 & 0 \\
0 & \mathrm{v}_{\alpha} & \mathrm{v}_{\beta} \\
0 & \mathrm{v}_{\beta} & -\mathrm{v}_{\alpha}
\end{array}\right] \quad\left[\begin{array}{c}
\mathrm{i}_{0} \\
\mathrm{i}_{\alpha} \\
\mathrm{i}_{\beta}
\end{array}\right]
$$

The instantaneous real power (p) and instantaneous zero sequence power $\left(\mathrm{P}_{0}\right)$, determined in $\alpha \beta 0$ coordinates, can be associated to the instantaneous three phase active power (p) determined

$P_{3 \infty}=v_{\alpha} i_{\alpha}+v_{\beta} i_{\beta}+v_{0} i_{0} v_{a} i_{a}+v_{b} i_{b}+v_{c} i_{c}$

This can be simplified in case of three wire systems as

$$
\mathrm{P}_{3 \phi}=\mathrm{p}=\mathrm{v}_{\alpha} \mathrm{i}_{\alpha}+\mathrm{v}_{\beta} \mathrm{i}_{\beta}
$$

Then, concept of the instantaneous imaginary power (q), defined as:

$$
\mathrm{q}=\mathrm{v}_{\beta} \mathrm{i}_{\alpha}+\mathrm{v}_{\alpha} \mathrm{i}_{\beta}
$$

Thus power can also be express as

$$
(\mathrm{p}=\overline{\mathrm{p}}+\widetilde{\mathrm{p}}) \text { and }(\mathrm{q}=\overline{\mathrm{q}}+\overline{\mathrm{q}})
$$

Where $(\overline{\mathrm{p}})$ and $(\overline{\mathrm{q}})$ represent the average and oscillating components of (p) and (q). The oscillating parts of (p) and (q) are related to the occurrence of unbalanced and distorted voltages and currents. Finally, after some mathematical manipulation, each power term from (6) can be contemplated to a current term which can be directly corelated to the operation of selective shunt compensation.

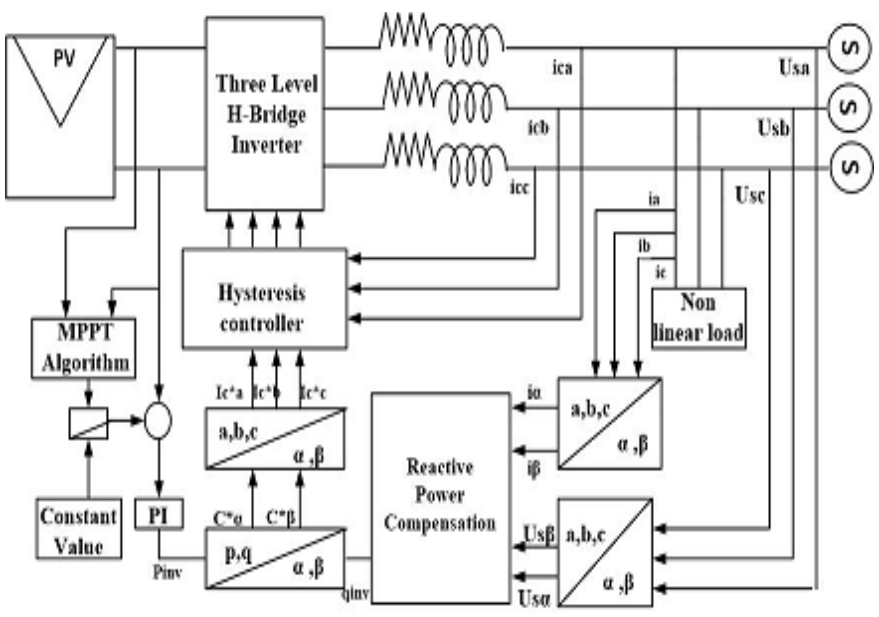

Fig. 2 Block diagram of pq 


\subsection{DQ control strategy}

In this technique, the load currents are transformed from the abc stationary reference frame to the dq synchronous reference frame in order to separate the fundamental positive and negative sequence components of instantaneous currents. The transformation to translate load currents from the abc Frame to the dq frame is given by:

$\left[\begin{array}{l}\mathrm{i}_{\mathrm{d}} \\ \mathrm{i}_{\mathrm{q}}\end{array}\right]=\sqrt{\frac{2}{3}}\left[\begin{array}{ccc}\cos (\theta) & \cos (\theta-2 \pi / 3) & \cos \left(\theta+\frac{2 \pi}{\mathrm{a}}\right) \\ -\sin (\theta) & -\sin \left(\theta-\frac{2 \pi}{\mathrm{a}}\right) & -\sin (\theta+2 \pi / 3\end{array} \mid\left[\begin{array}{c}\mathrm{i}_{\mathrm{a}} \\ \mathrm{i}_{\mathrm{b}} \\ \mathrm{i}_{\mathrm{c}}\end{array}\right]\right.$

The inverse transformation to transfer the currents from the dq frame to the abc frame is given by

$$
\left[\begin{array}{c}
\mathrm{i}_{\mathrm{a}} \\
\mathrm{i}_{\mathrm{b}} \\
\mathrm{i}_{\mathrm{c}}
\end{array}\right]=\sqrt{\frac{2}{3}}\left[\begin{array}{cc}
\cos (\theta) & -\sin (\theta \\
\cos (\theta-2 \pi / 3 & -\sin (\theta+2 \pi / 3 \\
\cos \left(\theta+\frac{2 \pi}{3}\right) & -\sin (\theta+2 \pi / 3
\end{array}\right]\left[\begin{array}{l}
\mathrm{i}_{\mathrm{d}} \\
\mathrm{i}_{\mathrm{q}}
\end{array}\right]
$$

The synchronization angle $(\theta)$ is a time-variant angle that represents the angular position of the dq synchronous reference frame. This frame is rotating at a constant speed in synchronism with the three-phase AC voltages.

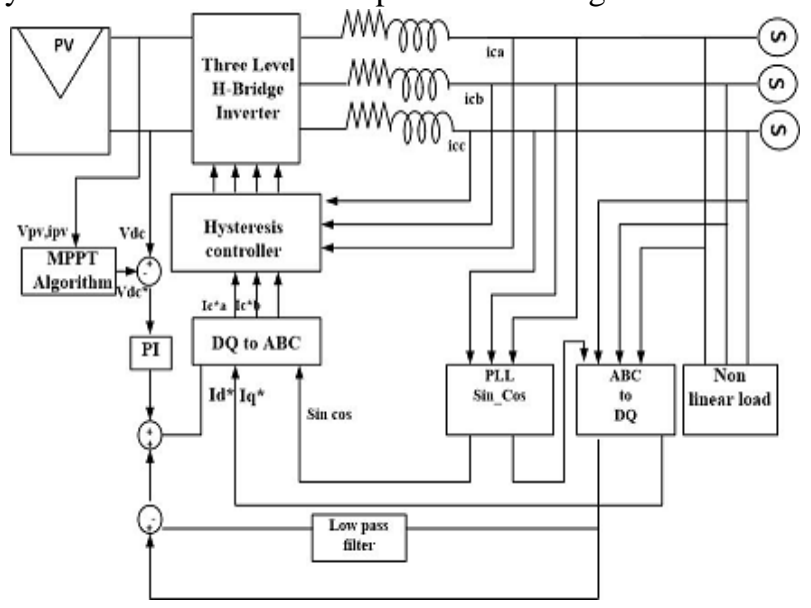

Fig. 3 Block diagram of dq

As it is illustrated in fig 3, first is detected by a Phase-locked Loop (PLL) and then, the load currents are transferred to dq frame using equation (7). The load currents in dq frame pass through low pass filter to extract its constant part representing the fundamental positive sequence components of load currents in dq frame. Finally, by using equation (8), those components are transferred from dq frame to the abc frame. In this frame, ( ${ }_{\text {pdqf }}$ ) is used to represent the fundamental positive sequence load current. If the negative angle $(-\theta)$ instead of $\theta$ is used here, the resulting currents represent the fundamental negative sequence. The fundamental negative sequence rotates with the same angular frequency as the fundamental positive sequence but in opposite direction. Using $-\theta$ in equation (7) makes the fundamental negative sequence component constant in dq frame, which can be easily extracted by low pass filters. Finally, by using equation (8) with those components are transferred from dq fame to the abc frame. In this frame ( $i_{n d q f}$ ) is used to represent the load current fundamental positive sequence. The oscillatory part of load currents $\left(i_{h}\right)$ is related to harmonic currents and can be determined by subtracting the fundamental negative and positive sequence from the total load currents, as follow.

$$
\left[\begin{array}{c}
i_{\text {ah }} \\
i_{\text {bh }} \\
i_{c}
\end{array}\right]=\left[\begin{array}{c}
i_{\text {a }} \\
i_{b} \\
i_{c}
\end{array}\right]\left[\begin{array}{l}
i_{\text {apdqf }} \\
i_{\text {bpdqf }} \\
i_{\text {cpdqf }}
\end{array}\right]-\left[\begin{array}{l}
i_{\text {andqf }} \\
i_{\text {bndqf }} \\
i_{\text {cndqf }}
\end{array}\right]
$$

\subsection{Conservative power theory.}

The variables (voltages and currents, as well as their integrals and derivatives) defined by the authors (Tenti et al 2003) of the CPT satisfy Kirchhoff's Voltage and Current Laws. Thus, according to Tellegen's Theorem, it can be stated that each dot product of these Variables is a conservative quantity [13] Thus the concept of active power and reactive energy conservation under generic conditions of unbalance and/or harmonic distortion is introduced. In this method a current decomposition methodology was proposed, where each resulting term is related to a specific load characteristic (power consumption, power storage, unbalance and nonlinearities). Main quantities used in CPT-based compensation methodologies are defined in set of real, continuous and periodic quantities $\mathrm{T}$ (time period), Fundamental frequency $(\mathrm{f}=1 / \mathrm{T})$, angular frequency $(\omega=2 \pi)$ .Voltage (v) and Current (i) vectors measured at a given network port (phase variables are indicated with subscript "m"). The instantaneous power was defined by the scalar product by the scalar product

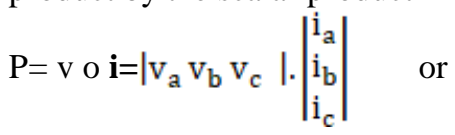

$\mathrm{P}(\mathrm{t})=\underline{\mathrm{v}} \cdot \underline{\mathrm{i}}=\sum_{\mathrm{k}=0}^{\mathrm{m}}=\mathrm{v}_{\mathrm{m}} \mathrm{i}_{\mathrm{m}}$

While the instantaneous reactive energy was defined

$\mathrm{P}(\mathrm{t})=\underline{\mathrm{V}} \cdot \underline{\mathrm{i}}=\sum_{\mathrm{k}=0}^{\mathrm{m}}=\mathrm{v}_{\mathrm{m}} \mathrm{i}_{\mathrm{m}}$

While the instantaneous reactive energy was defined

$\mathrm{w}=\widehat{\mathrm{v} o i}=\left[\begin{array}{lll}\widehat{\mathrm{v}_{\mathrm{a}}} & \widehat{\mathrm{v}_{\mathrm{b}}} & \widehat{\mathrm{v}_{\mathrm{c}}}\end{array}\right] \mathrm{o}\left|\begin{array}{l}\mathrm{i}_{\mathrm{a}} \\ \hat{i}_{\mathrm{b}} \\ i_{\mathrm{c}}\end{array}\right| \quad$ or

$\mathrm{W}(\mathrm{t})=\underline{\hat{\mathrm{v}}}_{-} \cdot \underline{\mathbf{i}}=\mathrm{v}_{\mathrm{m}} \mathrm{i}_{\mathrm{m}}$

where $\widehat{\mathrm{v}}$ is defined as the vector containing the unbiased integrals of the phase voltages. In other words, this quantity $\widehat{v}$ is calculated by the difference between the time integral and its average value, as shown below:

$$
\begin{aligned}
& \hat{\mathrm{v}}_{\mathrm{m}}=\mathrm{v}_{\int \mathrm{m}_{-}} \hat{\mathrm{v}}_{\int \mathrm{m}} \mathrm{v}_{\int \mathrm{m}}=\int_{0}^{T} \mathrm{v}_{\mathrm{m}}(\boldsymbol{\tau}) \mathrm{d} \boldsymbol{\tau} \\
& \hat{\mathrm{v}}_{\int \mathrm{m}}=\frac{1}{T} \int_{0}^{T} \mathrm{v}_{\mathrm{m}}(\boldsymbol{\tau}) \mathrm{d} \boldsymbol{t}
\end{aligned}
$$

Where according to theory phase voltages are measured with respect to a virtual reference point, in the case of three-phase three-wire circuits, and with respect to the neutral conductor, in the case of single or three-phase four-wire circuits. In this theory, Active power is the average power transferred (converted into work), and its definition is identical to that of conventional active power. 


\section{Performance of Three Level H-Bridge Inverter in Grid Connected Solar PV for Multifunctional Operations using Different Control Techniques}

Reactive energy, in turn, is a new definition that represents the average energy stored in the multiphase grid in generic conditions, including waveform distortions and unbalances. Both P and W satisfy Tellegen's Theorem and are therefore conservative in any grid, regardless of voltage and current waveform Here term $\mathrm{P}$ coincides, at any moment, with conventional active power $\mathrm{P}$ conv $=\mathrm{V}$ I $\cos \phi$. Conversely, reactive energy is related to conventional reactive power through the fundamental frequency $(\omega)$, so that $\mathrm{W}=\mathrm{Q}$ conv $/ \omega$ $=\mathrm{V}$ I $\sin \phi / \omega$. Thus, conventional reactive power is associated with the frequency of the electrical grid, whereas the reactive energy proposed by the CPT is independent of frequency, making it interesting for systems with possible frequency variations, such as micro-grids. From a practical perspective, it is sufficient to calculate for the average value by means of frequency adaptive algorithms or simply low-pass filters, so that both the active power and the reactive energy are immune to variations in mains frequency. Based on these definitions, the phase currents were decomposed into the following subcomponents: balanced active currents, balanced reactive currents, unbalanced ac the corresponding average values of (12) and (13) are the Active power

$\mathrm{P}=\overline{\mathrm{p}}=(\underline{\mathrm{v}} \cdot \underline{\mathrm{i}})=\frac{1}{T} \int_{0}^{T} \cdot \underline{\mathrm{v}} \cdot \underline{\mathrm{i}} \mathrm{dt}=\sum_{m=1}^{M} \mathrm{P}_{\mathrm{m}}$

And Reactive Energy

$\mathrm{W}=\overline{\mathrm{p}}=\left(\underline{\hat{\mathrm{v}}}_{-} \cdot \underline{\mathrm{i}}\right)=\frac{1}{T} \int_{0}^{T} \hat{\mathrm{v}} \cdot \underline{\mathrm{i}} \mathrm{dt}=\sum_{m=1}^{M} \mathrm{~W}_{\mathrm{m}}$

Where ( $\left.\underline{\hat{v}}_{-}\right)$is the unbiased integral of the voltage vector. Based on the above definitions the phase currents are decomposed into three basic current components.

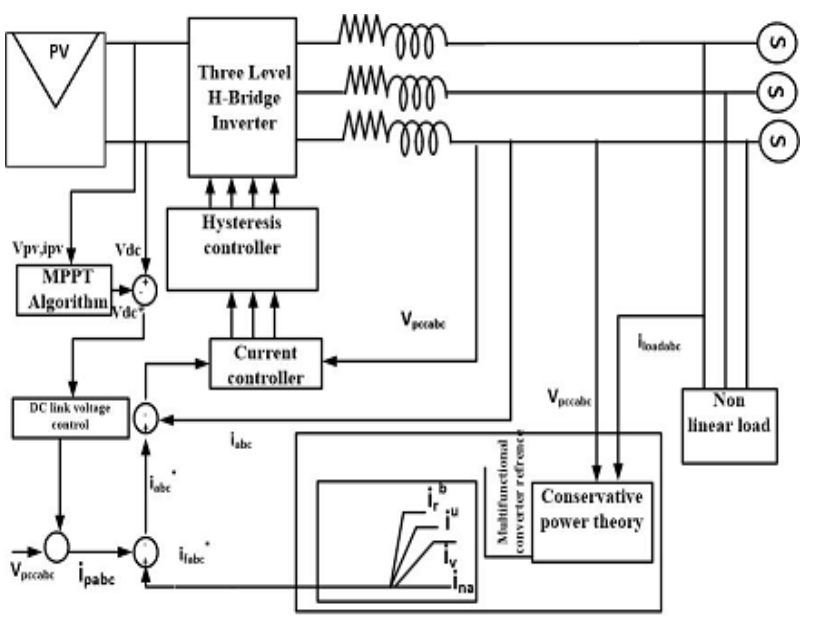

Fig. 4 Block diagram of $\mathrm{cpt}$

Active phase currents are defined by

Where $\left(G_{m}\right)$ is the equivalent phase conductance

Reactive phase currents are given by

$\mathrm{i}_{\mathrm{am}}=\frac{\left(\mathrm{v}_{\mathrm{m}} \mathrm{i}_{\mathrm{m}}\right)}{\left\|\mathrm{v}_{\mathrm{m}}\right\| 2} \quad \mathrm{v}_{\mathrm{m}}=\frac{\mathrm{Pm}}{\mathrm{v}_{\mathrm{m}}^{2}} \mathrm{~V}_{\mathrm{m}}=\mathrm{G}_{\mathrm{m}} \mathrm{V}_{\mathrm{m}}$ $\mathrm{i}_{\mathrm{rm}}=\frac{\left(\widehat{\mathrm{v}_{\mathrm{m}}} \mathrm{i}_{\mathrm{m}}\right)}{\left\|\mathrm{v}_{\mathrm{m}}\right\| 2} \widehat{\mathrm{v}}_{\mathrm{m}}=\frac{\mathrm{Wm}}{\mathrm{Vm}_{2}} \widehat{\mathrm{v}}_{\mathrm{m}}=\mathrm{B}_{\mathrm{m}} \widehat{\mathrm{v}}_{\mathrm{m}}$

Where $\left(B_{m}\right)$ is the equivalent phase reactivity

Void phase currents are the remaining current terms.

$\underline{\mathrm{i}}_{\mathrm{vm}}=\underline{\mathrm{i}}_{\mathrm{m}}-\underline{\mathrm{i}}_{\mathrm{am}}-\underline{\mathrm{i}}_{\mathrm{rm}}$

Which do not convey any active power or reactive energy. The active and reactive phase currents can be further decomposed into balanced and unbalanced terms.

$\mathrm{T}_{\underline{\mathrm{T}}_{\mathrm{am}}^{\mathrm{b}}}^{\mathrm{b}}=\frac{(\mathrm{v}, \mathrm{i})}{\|\mathrm{v}\| 2} \underline{\mathrm{V}}_{\mathrm{m}}=\frac{\mathrm{P}}{\mathrm{v}^{2}} \underline{\mathrm{V}}_{\mathrm{m}}=\mathrm{G}^{\mathrm{b}} \underline{\mathrm{V}}_{\mathrm{m}}$

the balanced active currents have been defined asThese currents represent the minimum portion of the phase currents which could be associated with a balanced equivalent circuit, responsible for conveying the total active power $(\mathrm{P})$ in the circuit, under certain voltage conditions.

The balanced reactive currents have been defined as:

$\underline{\mathrm{i}}_{\mathrm{rm}}^{\mathrm{b}}=\frac{(\widehat{\hat{\mathrm{V}}}, \underline{\mathrm{i}})}{\|\underline{\hat{\mathrm{v}}}\|_{2}} \underline{\hat{\mathrm{v}}}_{m=} \frac{\mathrm{W}}{\hat{\mathrm{V}}^{2}} \mathrm{v}_{\mathrm{m}}=\mathrm{B}^{\mathrm{b}} \underline{\hat{\mathrm{v}}}_{\mathrm{m}}$

They represent the minimum portion of the phase currents which could be associated with a balanced equivalent circuit responsible for conveying the total reactive energy $(\mathrm{W})$ in the circuit. The unbalanced active currents are calculated by the difference between

$$
\mathrm{i}_{\mathrm{am}}^{\mathrm{u}}=\mathrm{i}_{\mathrm{am}}-\mathrm{i}_{\mathrm{am}}^{\mathrm{b}}=\left(\mathrm{G}_{\mathrm{m}}-\mathrm{G}^{\mathrm{b}}\right) \mathrm{V}_{\mathrm{m}}
$$

In the same way, the unbalanced reactive currents are

$$
\mathrm{i}_{\mathrm{rm}}^{\mathrm{u}}=\mathrm{i}_{\mathrm{rm}}-\mathrm{i}_{\mathrm{rm}}^{\mathrm{b}}=\left(\mathrm{B}_{\mathrm{m}}-\mathrm{B}^{\mathrm{b}}\right) \hat{v}_{m}
$$

Thus the total unbalance phase currents are defined as in (18)

$\mathrm{I}_{\mathrm{m}}^{\mathrm{u}}=\mathrm{I}_{\mathrm{am}}^{\mathrm{u}}+\mathrm{I}_{\mathrm{rm}}^{\mathrm{u}}$

Therefore, the measured current vector can be split as

$\underline{\mathrm{i}}=\underline{\mathrm{i}}_{\mathrm{a}}^{\mathrm{b}}+\underline{\mathrm{i}}_{\mathrm{r}}^{\mathrm{b}}+\underline{\mathrm{i}}_{\mathrm{a}}{ }^{\mathrm{u}}+\underline{\mathrm{i}}_{r}^{\mathrm{u}}$

For example, the components of unbalanced currents or of void currents can be used to compensate, selectively or not, for load unbalances and/or nonlinearities. Likewise, the reactive energy (or power) can be compensated in any multiphase system,. By definition, all the previous current components are orthogonal to each other so that their RMS value results.

$I=\sqrt{I_{\mathrm{a}}^{\mathrm{b}^{2}}+\mathrm{Ir}_{\mathrm{r}}^{\mathrm{b}^{2}}+\mathrm{I}_{\mathrm{a}}^{\mathrm{u}^{2}}+\mathrm{I}_{\mathrm{r}}^{\mathrm{b}^{2}}+\mathrm{I}_{\mathrm{v}}^{2}}$ 
Similarly, apparent power (A) can be defined by

$\mathrm{A}=\|\mathrm{v}\| \cdot\|\boldsymbol{i}\|$ or

$A=\|v\| \cdot \sqrt{I_{a}^{b^{2}}+I_{r}^{b^{2}}+I_{a}^{u^{2}}+I_{r}^{b^{2}}+I_{v}^{2}}$

$\mathrm{A}=\sqrt{\mathrm{P}^{2}+Q^{2}+N_{a}^{2}+N_{r}^{2}+D^{2}}$

Where $\mathrm{P}=V \mathrm{i}_{\mathrm{a}}^{\mathrm{b}}$ active power;

$\mathrm{Q}=\mathrm{V} \mathbf{I}_{\mathbf{r}}^{\mathbf{b}}$ is reactive power;

$\mathrm{Na}=\mathrm{VI}_{\mathrm{a}}^{\mathbf{u}}$ is unbalanced active power;

$\mathrm{N}_{r} \mathrm{r}=\mathrm{V} \mathbf{I}_{\mathbf{r}}^{\mathbf{u}}$ is unbalanced reactive power and

$\mathrm{D}=\mathrm{V} \mathbf{I}_{\mathbf{v}}$ is distortion power

CPT also defined the global power factor $(\lambda)$. This Type equation here factor is affected not only by the circulation of reactive power (Q) but also by load unbalances (N) and nonlinearities (D). $\lambda=\frac{P}{A} \quad$ Thus some of the portions of Eq. (23) can be applied for purposes of power conditioning regardless of the circuit's voltage and current waveforms, provided they are periodic able

Table I Simulation Parameter

\begin{tabular}{|c|c|c|}
\hline \multirow[t]{11}{*}{ Grid } & Voltage & $440 \mathrm{~V}$ \\
\hline & Frequency & $50 \mathrm{~Hz}$ \\
\hline & Open circuit voltage & $45.78 \mathrm{~V}$ \\
\hline & Short circuit current & $5.75 \mathrm{~A}$ \\
\hline & No of cell per module & 60 \\
\hline & $\begin{array}{l}\text { Series connected modules per } \\
\text { string }\end{array}$ & 10 \\
\hline & Parallel module & 1 \\
\hline & Irradiance(G) & $500 \sim 700$ \\
\hline & Temperature & $25^{0} \mathrm{C} \sim 35^{0} \mathrm{C}$ \\
\hline & Source resistance & $1 \times 10-3 \Omega$ \\
\hline & Source inductance & $1 \mathrm{x} 10-7 \mathrm{mH}$ \\
\hline \multirow{2}{*}{ Load } & $\begin{array}{l}\text { Three-Phase Diode Bridge } \\
\text { Rectifier With RL as output }\end{array}$ & $\begin{array}{l}\mathrm{R}=180 \Omega, \mathrm{L} \\
=11.20 \mathrm{mH}\end{array}$ \\
\hline & $\begin{array}{c}\text { Three-Phase Diode Bridge } \\
\text { Rectifier With RC as output }\end{array}$ & $\begin{array}{l}\mathrm{R}=100 \Omega \\
\mathrm{C}=250 \mu \mathrm{F}\end{array}$ \\
\hline
\end{tabular}

\section{RESULTS AND DISCUSSION}

The performance of the three-phase three level $\mathrm{H}$ bridge inverter as an active filter for pq, dq and CPT control technique is simulated in Matlab Simulink platform for various nonlinear as well as unbalanced loads. The parameters of the photovoltaic system and the electrical power system which were simulated are given in Tables 1 . Based on the block diagram of the control strategy in Fig.2, 3, 4 the proposed system was simulated figure 5, 6, 7 gives the waveforms of grid voltage, grid current, and load current, active and reactive powers of grid, inverter with nonlinear load. It is clear from simulation wave forms that proposed inverter is apart from supplying active power from PV panel to grid but also provide reactive support to grid. Figure 5, 6, 7 ,shows the dynamic performance of inverter with pq, dq, cpt control with variable irradiance and temperature in PV mode. The performance indices are source voltage Vs, Source current Is, $\mathrm{I}_{\mathrm{l}}$ is load current, combined active power of Grid, inverter, load and combined, reactive power of Grid, inverter, load these wave forms are taken for step change of temperature and irradiance. When the time is $\mathrm{t}=1 \mathrm{~s}$ the solar radiation is altered from $500 \mathrm{~W} / \mathrm{m} 2$ to $750 \mathrm{~W} / \mathrm{m} 2$ and temperature from $25^{\circ} \mathrm{C}$ to $35^{\circ} \mathrm{C}$. This has the effect of changing the amplitude of the current of the inverter and the grid .The increase in radiation results in an increase in the active power of PV system as shown in Figures, thus increasing the power of the inverter. At the same time there is a reduction of active power of the grid to the load when grid absorb the surplus of active power the phase of grid voltage $\left(\mathrm{V}_{\mathrm{sa}}\right)$ and grid current is $\left(\mathrm{I}_{\mathrm{sa}}\right)$ 180. It clearly shows the satisfactory operation of three phase three level H-bridge inverter for harmonic elimination, reactive power compensation and power factor correction.

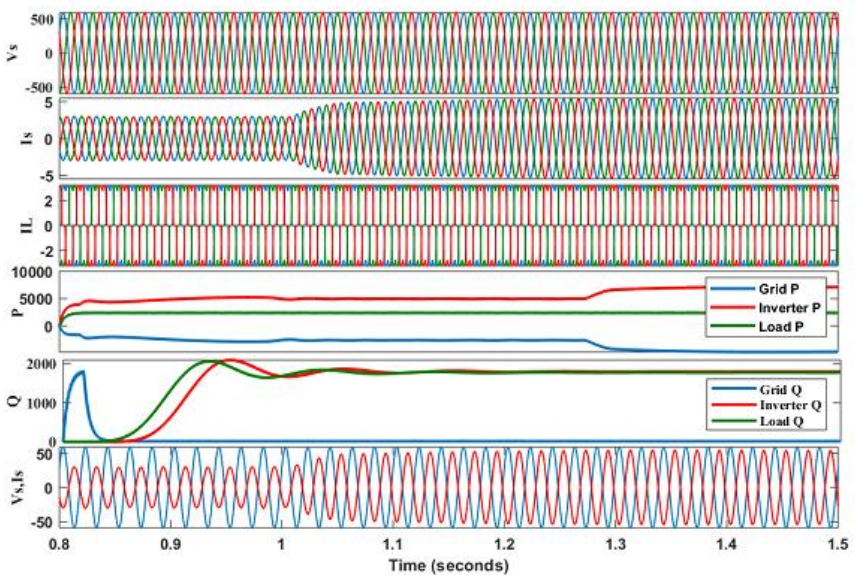

Fig. 5 Dynamic performance of inverter in PV mode with pq control

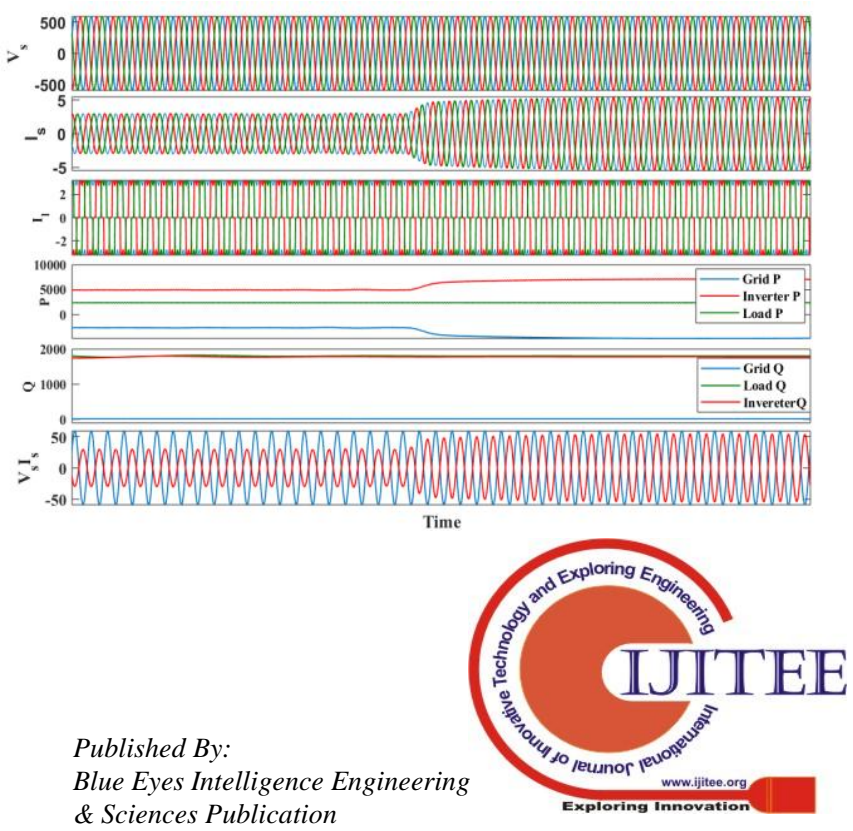




\section{Performance of Three Level H-Bridge Inverter in Grid Connected Solar PV for Multifunctional Operations using Different Control Techniques}

Fig. 6 Dynamic performance of inverter in PV mode with dq control

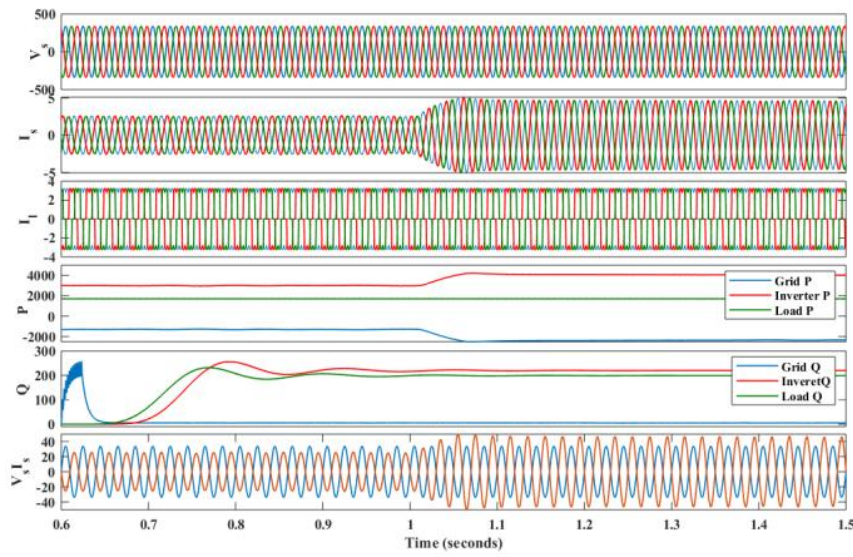

Fig. 7 Dynamic performance of inverter in PV mode with cpt control

Figure 8,9, 10 the STATCOM operation of inverter for all three control algorithm .Fig. also shows the voltage $\left(\mathrm{V}_{\mathrm{sa}}\right)$ and current of the grid $\left(\mathrm{I}_{\mathrm{sa}}\right)$ for the phase a. We observe that the grid current $\left(\mathrm{I}_{\mathrm{sa}}\right)$ and grid voltage $\left(\mathrm{V}_{\mathrm{sa}}\right)$ are in phase for DQ because all the reactive power of the load is compensated by the inverter while in pq and cpt reactive power compensation for same load is not taking place thus power factor correction is not proper. An inverter controller is proposed to work the PV solar system as STATCOM utilizing the PV inverter in the night time and the inverter utilizing for a real power generation at day time. It utilizes the entire solar farm inverter capacity in the night and the remainder inverter capacity after real power generation during the day, both of which remain unused in conventional solar farm operation. Different control techniques which are described here are used to control the inverter switching to function as STATCOM to improve the voltage profile. THD \% of the phase ' $A$ ' of source current is shown in figure 11 to 13 . It is observed that the THD of the source current are within IEEE-519-1992 standard limit of $5 \%$ for all three control. Table 2 shows the summarized results demonstrating the performance of inverter as active filter for all three control and various load.

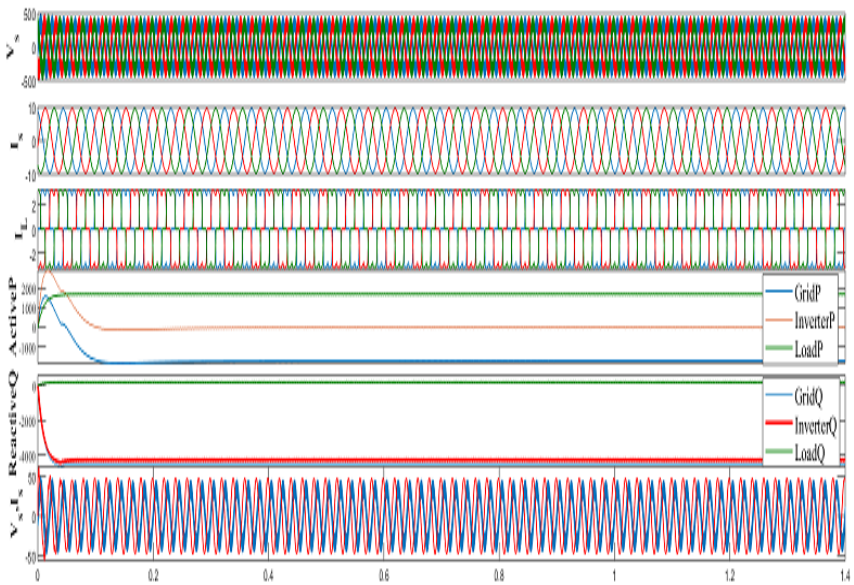

Fig. 8 Dynamic performance of inverter in STATCOM mode with pq control

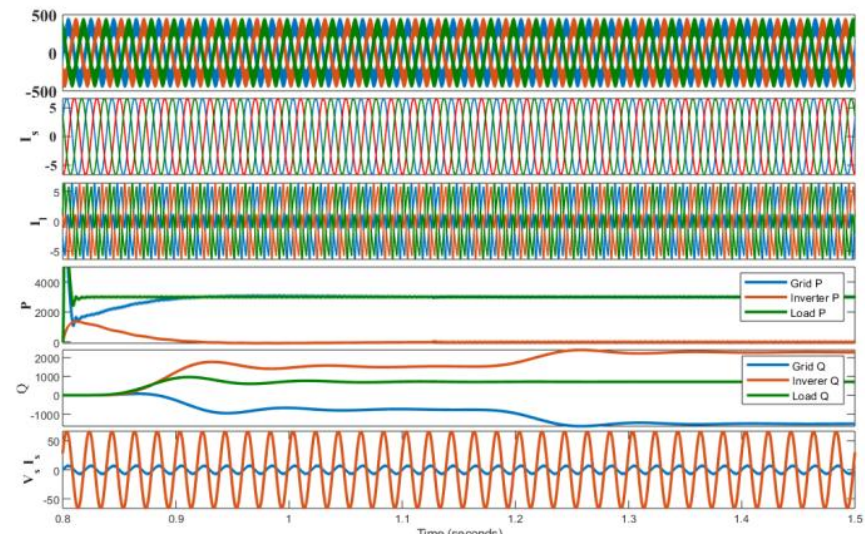

Fig. 9 Dynamic performance of inverter in STATCOM mode with dq control

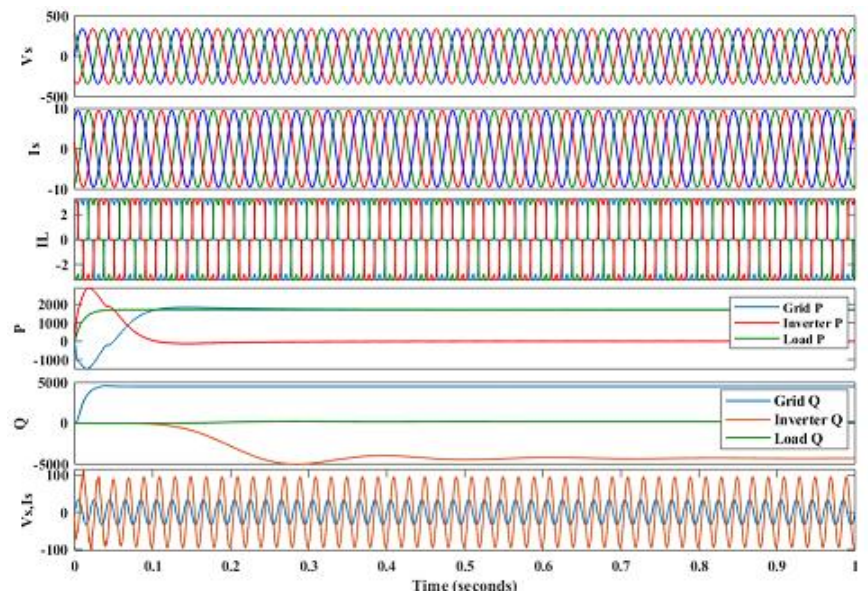

Fig.10 Dynamic performance of inverter in STATCOM mode with cpt control

\section{CONCLUSION}

The performance of inverter has been demonstrated for harmonic elimination, reactive power compensation and power factor correction for nonlinear load in PV mode and STATCOM modes of operation. The performance of inverter has been found satisfactory under varying temperature and irradiance conditions for all three control techniques. From simulation results, it is found, that proposed system apart from the active and reactive power control it is able to compensate harmonics of the load uninterruptedly for various control where the load is non-linear.. After Investigations of all three control technique, it is found that all three control are suited for three phase three level inverter for PV application but $\mathrm{CPT} \& \mathrm{PQ}$ control technique are not convenient in STATCOM mode because this control reactive power compensation for nonlinear load is not appropriates This system, due to its simplicity and ability to provide many functions to the photovoltaic system simultaneously is a great solution for future distribution grids Use of three phase threelevel converters has several merits, like, the modularity in the system configuration with increased reliability, also allowing the use of independent DC link voltages, no need to used additional dc- dc boost cover/transformer as in case of traditional two level inverter. 
These features by themselves already make this topology suited to interface medium and high power grid connected applications Because of the 24hrs utilization of multilevel multifunctional inverter it is possible to reduce the cost of installation of extra filters, boost converters and FACTS device and also improve the overall efficiency of system.

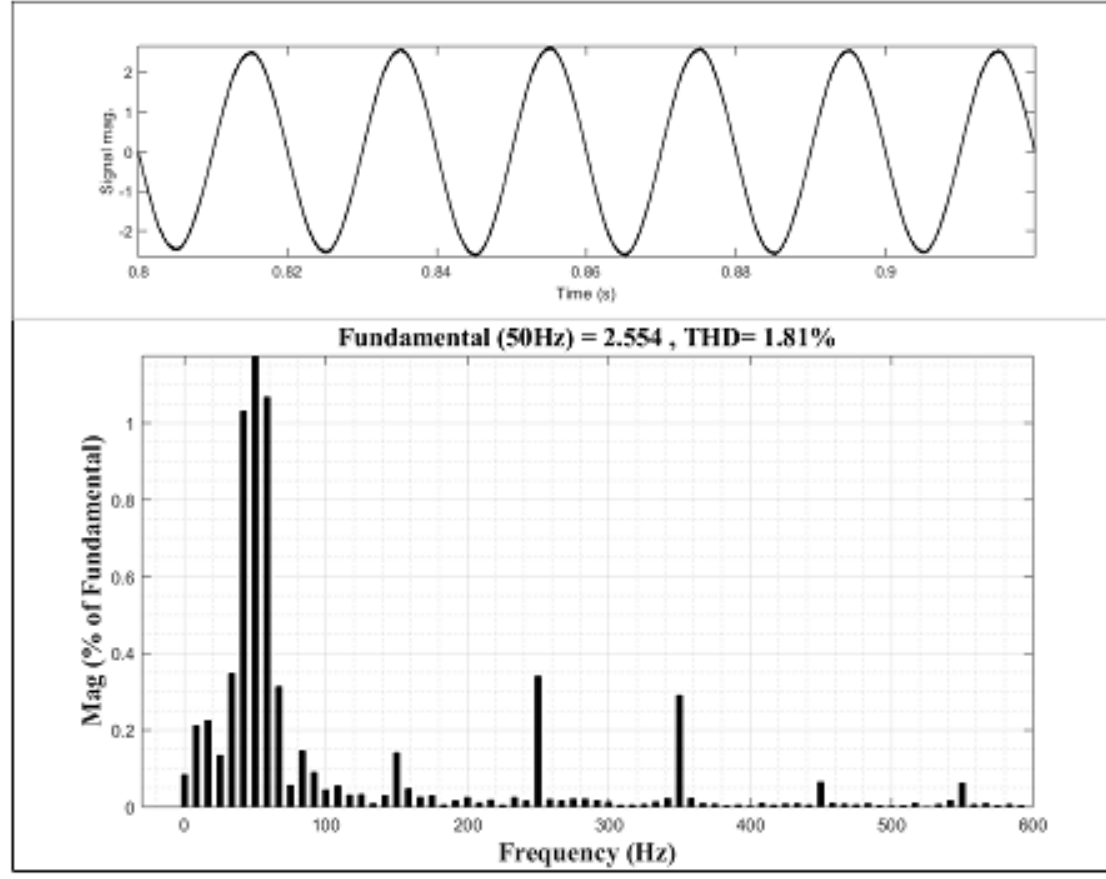

Fig.11 FFT of Grid current in PV mode with dq control

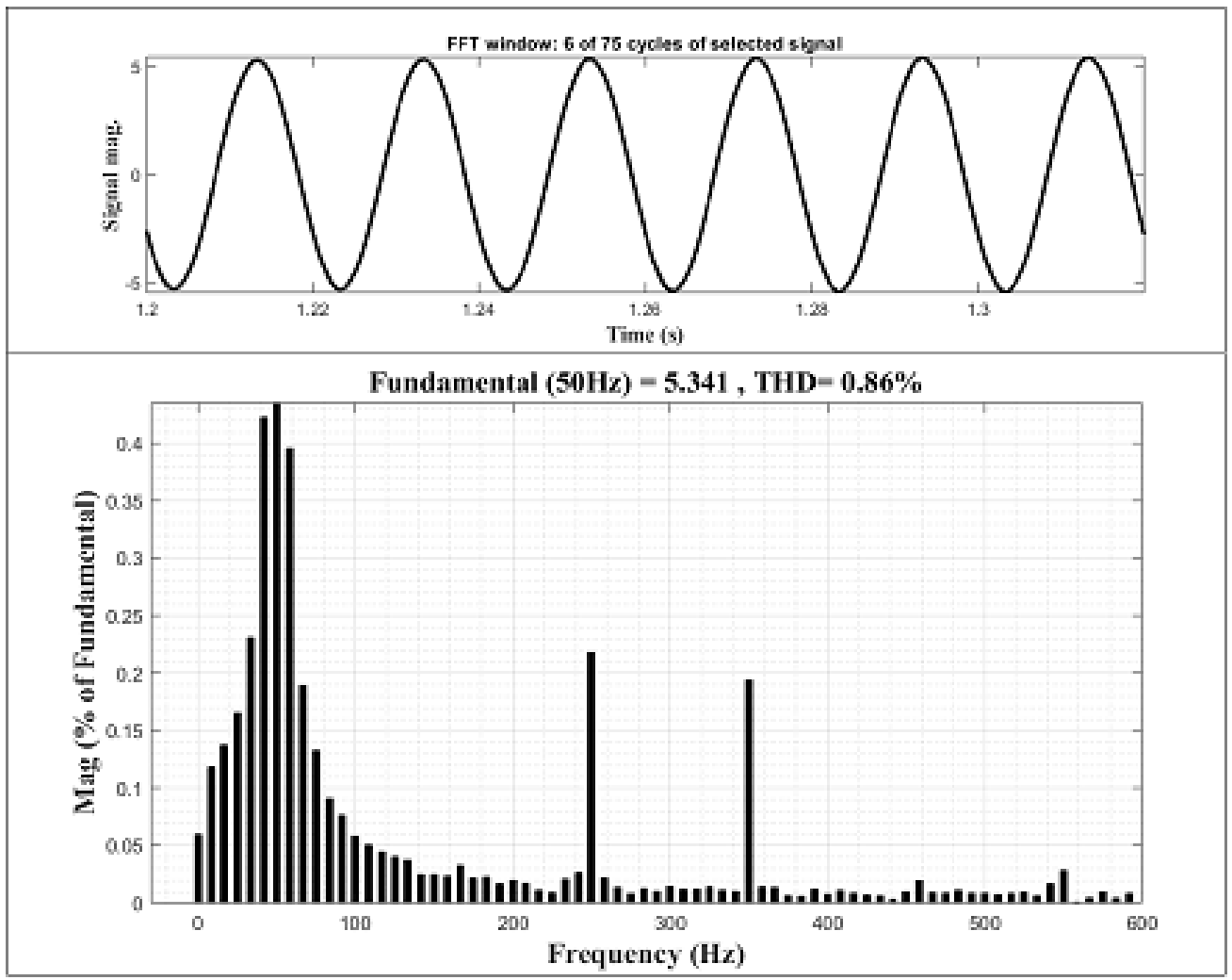

Fiig.12 FFT of Grid current in PV mode with pq control 

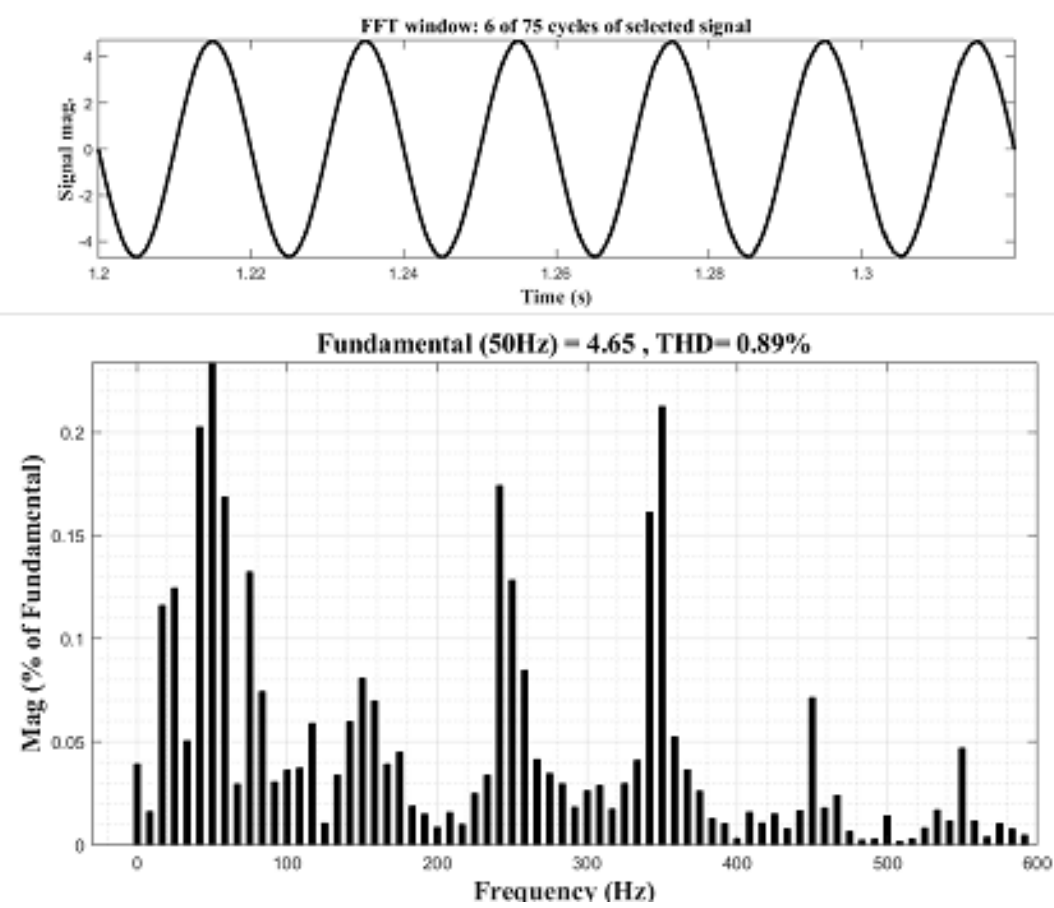

Fig.13 FFT of Grid current in PV mode with cpt control

Table II Performance of inverter in different operating modes

\begin{tabular}{|c|c|c|c|}
\hline Operating Mode & Control Technique & $\begin{array}{c}\text { Source current THD for Nonlinear load } \\
\text { (Diode Rectifier) }\end{array}$ \\
\cline { 3 - 4 } & & $\begin{array}{c}\text { With RL as output of } \\
\text { rectifier }\end{array}$ & $\begin{array}{c}\text { With RC as } \\
\text { output of rectifier }\end{array}$ \\
\hline \multirow{2}{*}{ PV Mode } & PQ & $0.86 \%$ & $2.04 \%$ \\
\cline { 2 - 4 } & DQ & $1.81 \%$ & $3.47 \%$ \\
\cline { 2 - 4 } & CPT & $0.89 \%$ & $2.73 \%$ \\
\hline \multirow{2}{*}{ STATCOM } & PQ & $1.14 \%$ & $0.62 \%$ \\
\cline { 2 - 4 } & DQ & $0.48 \%$ & $0.63 \%$ \\
\cline { 2 - 4 } & CPT & $1.14 \%$ & $0.51 \%$ \\
\hline
\end{tabular}

\section{REFERENCES}

1. J. Rodríguez, J. S. Lai, and F. Z. Peng, "Multilevel inverters: A survey of topologies, controls, and applications," IEEE Trans. Ind. Electron., vol. 49, no. 4, pp. 724-738, Aug. 2002.

2. L. G. Franquelo, J. Rodriguez, J. I. Leon, S. Kouro, R. Portillo, and M. A. M. Prats, "The age of multilevel converters arrives," IEEE IndElectron. Mag., vol. 2, no. 2, pp. 28-39, Jun. 2008.

3. M. Malinowski, K. Gopakumar, J. Rodriguez, and M. A. Perez, “A survey on cascaded multilevel inverters," IEEE Trans. Ind. Electron., vol. 57, no. 7, pp. 2197-2206, Jul. 2010:

4. $\quad$ Peng FZ, McKeever JW, Adams DJ. A power line conditioner using cascade multilevel inverters for distribution systems. IEEE Trans Ind Appl1998; 34(6):1293-8

5. Kouro, S., Malinowski, M., Gopakumar, K., et al.: 'Recent advances and industrial applications of multilevel converters', IEEE Trans. Ind. Electron., 2010, 57, (8), pp. 2553-2580

6. Peng FZ, Lai JS, McKeever JW, Van Coevering J. A multilevel voltage-source inverter with separate DC sources for static VAR generation. IEEE Trans Ind Appl 1996; 32:1130

7. Peng FZ, Lai JS, McKeever JW, Van Coevering J. A multilevel voltage-source inverter with separate DC sources for static VAR generation. IEEE Trans Ind Appl 1996; 32:1130

8. B. Wu, and Narimani, M., 2017. High-power converters and AC drives (Vol. 59). John Wiley \& Sons.

9. Rajiv K.Varma , and Ehsan M. Siavashi. "PV- STATCOM-A New Smart Inverter for Voltage Control in Distribution Systems." IEEE Transactions on Sustainable Energy (2018)
10. H. Akagi, E. H. Watanabe, M. Aredes, And Instantaneous Power Theory and Applications to Power Conditioning, New Jersey: IEEE Press/Wiley Interscience, 2007, ISBN: 978-0-470-10761

11. B. Singh, K. Al-Haddad and A. Chandra, "A new control approach to 3-phase active filter for harmonics and reactive power compensation",-IEEE Trans. on Power Systems, vol. 46, no. 5, pp.133 -138 , Oct

12. H. Akagi, Y. Kanazawa, A. Nabae "Instantaneous reactive power compensators comprising switching devices without energy storage components", IEEE Trans on Industry Appl, vol.3, pp.625-630, 1984.

13. P. Tenti, H. K. M. Paredes, and P. Mattavelli, "Conservative Power Theory, a framework to approach control and accountability issues in smart microgrids," IEEE Trans. Power Electron., vol. 26, no. 3, pp. 664-673, 2011.

14. Tsengenes, G., Adamidis, G., 2011. Investigation of the behavior of a three phase grid-connected photovoltaic system to control active and reactive power. Electric Power Systems Research 81 (1), 177-184

15. Mortezaei, A., Lute, C., Simoes, M. G., Marafao, F.P., Boglia, A.:'PQ,DQ and CPT control method for shunt active compensators-a comparative study,' in Proc. IEEE ECCE, Pittsburgh, PA, USA, September 2014, pp. 2994-3001

16. Patnaik SS, Panda AK. Real-time performance analysis and comparison of various control schemes for particle swarm optimization-based shunt active Power filters. Electr Power Energy Syst 2013; 52:185-97 
17. L. Liu, H. Li, Y. Xue, W. Liu, "Reactive power compensation and optimization strategy for grid-interactive cascaded photovoltaic systems, "submitted to IEEE Trans. Power Electron. 2014

18. Rajiv K. Varma, Vinod Khadkikar, and Ravi Seethapathy. "Nighttime application of PV solar farm as STATCOM to regulate grid voltage." IEEE transactions on energy conversion 24, no. 4 (2009): 983-985.

\section{AUTHORPROFILE}

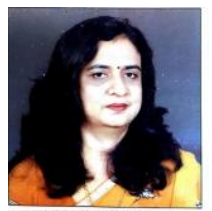

Darshni M. Shukla, Darshni M. Shukla, Dept. of Electrical Engineering Government Engineering College Surat, India Gujrat technological University, darshnishukla@yahoo.com

Darshni Shukla is assistant professor in government engineering college Surat. She has done B.E. electrical from I.G. government engineering college SAugor and M.Tech. in power electronics \& electrical drives from SVNIT Surat. Currently she is perusing P.HD. from Gujarat technological university Ahmedabad.

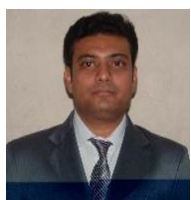

Naimish Zaveri, Dr. Naimish Zaveri ,Dept. of Electrical Engineering, CK Pithawala College of Engineering \&Technology, College Surat, India Gujrat technological University

Dr. Naimish Zaveri is Professor and Head of Electrical Engineering in C. K. Pithawalla College of Engineering and Technology, Surat. He is PHD., M. E (Power System), B.E (Electrical) and his academics experience is 18 years, 6 months. His area of interests Power System Operation, Control and Power Quality Issues. 